\title{
Overlap Between Constipation and Gastroesophageal Reflux Disease in Japan: Results From an Internet Survey
}

\author{
Naotaka Ogasawara, ${ }^{*}$ Yasushi Funaki, Kunio Kasugai, Masahide Ebi, Yasuhiro Tamura, Shinya Izawa, and Makoto Sasaki \\ Division of Gastroenterology, Department of Internal Medicine, Aichi Medical University School of Medicine, Nagakute, Aichi, Japan
}

\begin{abstract}
Background/Aims
Detailed evaluations of overlapping constipation and gastroesophageal reflux disease (GERD) have not been conducted in Japan. The REACTION-J2 study examined the overlap of these diseases in Japan.

\section{Methods}

This internet-based survey recruited participants from general public survey panels. Questions included demographic and medical data and assessments based on validated measures for constipation and GERD. Associations between background factors affecting constipation/GERD overlap, disease measures, and treatment were also evaluated.

\section{Results}

Among 10000 survey responses received, functional constipation (Rome IV diagnostic criteria) was reported by 439 participants; chronic constipation (Japanese guidelines) by 3804 participants; and subjective constipation symptoms by 2563 participants. The number of participants with constipation/GERD overlap ranged from 73 to 1533 depending on the criteria used. Regardless of the definition used, all GERD groups had significantly higher odds of being constipated than non-GERD participants: the OR (95\% CI) for all 9 combinations of definitions ranged between $1.56(1.21,2.01)$ and $2.67(2.44,2.92)(a l l P \leq 0.001)$. Straining, hard stools, and sensations of incomplete evacuation and anorectal obstruction/blockage, according to chronic constipation criteria, were common. Participants with constipation/GERD overlap had poorer quality of life $(P<0.001)$ and worse GERD symptom scores $(P<0.001)$. The frequency of abnormal stools was highest $(P<0.001)$ in the constipation/GERD overlap group. In the overlap group, $52.4 \%$ and $26.0 \%$ used gastric and constipation medication, respectively.
\end{abstract}

\section{Conclusion}

Individuals with constipation/GERD overlap tend to have worsened symptoms and quality of life.

(J Neurogastroenterol Motil 2022;28:291-302)

Key Words

Constipation; Gastroesophageal reflux; Quality of life; Surveys and questionnaires; Therapeutics

Received: March 28, 2021 Revised: None Accepted: May 7, 2021

(a) This is an Open Access article distributed under the terms of the Creative Commons Attribution Non-Commercial License (http://creativecommons. org/licenses/by-nc/4.0) which permits unrestricted non-commercial use, distribution, and reproduction in any medium, provided the original work is properly cited.

*Correspondence: Naotaka Ogasawara, MD, PhD

Division of Gastroenterology, Department of Internal Medicine, Aichi Medical University School of Medicine, 1-1 Yazakokarimata, Nagakute, Aichi 480-1195, Japan

Tel: +81-561-62-3311, Fax: +81-561-62-1508, E-mail: nogasa@aichi-med-u.ac.jp 


\section{Introduction}

Chronic constipation is a common disorder in adults. ${ }^{1,2}$ In Japan, the prevalence of constipation-related complaints in 2016 was reported to be $2.5 \%$ in males and $4.4 \%$ in females, ${ }^{3}$ although a recent internet survey found a higher self-reported prevalence of $19.1 \%$ in males and $37.5 \%$ in females. ${ }^{4}$ When evaluated by age, the prevalence was reported to be $6.5 \%$ in males and $8.1 \%$ in females over 65 years of age. ${ }^{3}$

In October 2017, the "Clinical Practice Guideline for Chronic Constipation 2017" prepared by the Study Group for the Diagnosis and Treatment of Chronic Constipation of the Association of the Japanese Society of Gastroenterology was published (Chronic constipation medical care guideline 2017: https:/www.nankodo.co.jp/ g/g9784524255757/). However, despite the availability of management guidelines and evidence-based treatments, there is a paucity of data on the real-world status of Japanese individuals with chronic constipation. A survey initiated in 2016 (REACTION-J) to evaluate constipation within the general Japanese population found that $51.5 \%$ were aware that they have constipation. REACTION-J also found that stool abnormalities (hard or diarrheal) were associated with reduced quality of life (QOL). Additionally, increased age, female sex, and the presence of diabetes mellitus, hemorrhoidal disease, or cerebrovascular disease were identified as risk factors for functional constipation. ${ }^{5}$

Many patients with functional gastrointestinal disorders (FGID), including constipation, have overlapping disorders. Constipation is often complicated by the presence of other FGIDs, and common etiologies, such as gastrointestinal (GI) dysfunction, psychosocial factors, visceral hypersensitivity, autonomic dysfunction, and history of GI infections, are considered to be likely causes. ${ }^{6}$ FGID has also been reported to be associated with gastroesophageal reflux disease (GERD). ${ }^{7}$ It has been known for many years that patients with FGIDs (including constipation) often report other symptoms commonly associated with GERD (such as heartburn, belching, bloating, and gas symptoms), and that this association occurs across different races and ethnicities, ${ }^{8,9}$ with a particularly strong association within Asian populations.

Evidence-based clinical practice guidelines for GERD were published in 2015 by the Japanese Society of Gastroenterology. The prevalence of erosive GERD in Japanese individuals was estimated to be approximately $10.0 \%$, and that of GERD, including heartburn symptoms, to be 2-fold higher. ${ }^{10}$ Moreover, the prevalence of GERD has increased in recent years, due to increases in gastric acid secretion, decreases in Helicobacter pylori infection of the stomach, and widening dissemination of $H$. pylori eradication. Outside of Japan, GERD and dyspepsia have been reported to be complicated by constipation, with 1 study in the United States stating that constipation was present in $28 \%$ of patients with GERD and $30 \%$ with dyspepsia. ${ }^{11}$ The combination of GERD and functional constipation has also been reported in children. ${ }^{12,13}$ However, to date, there have been no detailed evaluations of overlapping constipation and GERD specific to Japan, and the proportion and status of affected individuals are unknown.

The current study, REACTION-J2, used data from an internet questionnaire to examine the frequency of overlapping constipation and GERD, the health status and coping mechanisms of affected individuals, and the details of current management, including the use of oral constipation medication. We intend for the resultant data to lay a foundation for drug selection and lifestyle choices in patients with constipation and GERD.

\section{Materials and Methods}

\section{Survey Design}

REACTION-J2 was an internet-based survey registered with the University Hospital Medical Information Network in Japan (Trial registration: UMIN000039688). The Ethics Review Committee of Aichi Medical University approved the study's implementation (Approval No. 2019-179). The study was conducted in accordance with the Declaration of Helsinki by the World Medical Association and the Ethical Guidelines for Medical Research (established on 22 December, 2014) by the Ministry of Education, Culture, Sports, Science and Technology and the Ministry of Health, Labour and Welfare.

The survey took place between 16-18 March, 2020. Participants were recruited from panels of the general public held by a survey company (Rakuten Insight Co, Ltd, Osaka, Japan). Inclusion and exclusion criteria were applied, and 10000 individuals meeting the eligibility criteria were enrolled after adjustments to reflect the general Japanese population's prefectural and age composition (according to the Japan Department of Statistics. October 1, 2019, https:/www.stat.go.jp/data/jinsui/2019np/index.html). The survey was closed to further participation when 10000 participants matching the required Japanese population characteristics were enrolled.

Full details of the questionnaire are provided in the Supplementary Method. Survey questions included demographic and medical 
data and questions based on validated measures for constipation and GERD (including Rome IV criteria, ${ }^{14}$ the GERD questionnaire [GerdQ], ${ }^{15}$ the Gastrointestinal Symptom Rating Scale [GSRS], ${ }^{16}$ the 8-item Short Form Health Survey Questionnaire [SF-8], ${ }^{17}$ the Constipation Scoring System [CSS], ${ }^{18}$ and the Frequency Scale for the Symptoms of GERD [FSSG] $)^{19}$

\section{Participants}

The inclusion criteria required participants to be males or females aged 20 to 69 years (inclusive), who provided informed consent for survey participation. Exclusion criteria were previous open surgery of the abdomen (excluding appendicitis); intestinal diseases such as inflammatory bowel disease, ulcerative colitis, and Crohn's disease; cancer of the GI tract; pregnancy; and inability to follow the study instructions.

\section{Endpoints}

The primary study endpoint was the frequency of overlap of constipation and GERD. The secondary endpoints for the study were the investigation of background factors affecting constipation and GERD overlap, the examination of the association between constipation and GERD overlap via each disease measure (SF-8, GSRS, CSS, and FSSG), and investigation of the association between background factors and items, including SF-8 score, GSRS score, FSSG score, Bristol stool form scale (BSFS) score, CSS score, satisfaction with bowel movement, treatment with gastric or constipation medication, and type of gastric or constipation medication. Using an FSSG score $\geq 8$ as a definition of GERD, the OR for chronic constipation and the relationships between FSSG subscale scores and chronic constipation were also investigated for further assessments.

For the evaluation of the primary and secondary endpoints, we used the following definitions and criteria. Constipation was diagnosed as per the following categories: functional constipation according to Rome IV diagnostic criteria; chronic constipation according to the Association of the Japanese Society of Gastroenterology Japanese guidelines; ${ }^{5}$ and the presence or absence of subjective symptoms of constipation. GERD was diagnosed according to 3 sets of criteria. 'Broad sense of GERD1' was based on the GerdQ and included participants who scored $\geq 1$ on the questions "How often did you have a burning feeling behind your breastbone (heartburn)?" or "How often did you have stomach contents (liquid or food) moving upwards to your throat or mouth (regurgitation)?" 'Broad sense of GERD2' was based on the GerdQ and included participants who scored $\geq 2$ on the same questions. 'Narrow sense of GERD' included participants who scored $\geq 8$ on the GerdQ. ${ }^{20}$

\section{Statistical Methods}

The sample size of 10000 participants was set to ensure that sufficient individuals with constipation and GERD were enrolled; no formal sample size calculations were employed. Categorical variables were reported using the number of cases and their percentage for each category. Summary statistics were used for continuous variables (mean, $\mathrm{SD}$, median, minimum, maximum, and quartiles). Height and weight were summarized by value after removing obvious outliers owing to participants' incorrect data entry, by excluding the highest and lowest values to remove $0.3 \%$ of the overall data.

For the primary endpoint, the degree of overlap between constipation and GERD was assessed for each of the 9 combinations generated using the 3 constipation diagnostic categories and the 3 GERD classifications. Data were expressed as ORs and 95\% CIs.

The secondary endpoints were evaluated as follows: for SF-8 analysis, we used the scoring program provided by iHOPE International (http://www.i-hope.jp/download/). For the FSSG, in addition to the total score, the subscores, reflux and dysmotility scores, were used for the evaluation. For satisfaction with bowel movements, responses were grouped as satisfied (very or somewhat satisfied) or dissatisfied (very or somewhat dissatisfied).

Logistic regression was conducted using pre-specified variables, and multivariate analysis was performed with the results from the univariate analysis and forced input method. The 2-sided significance level was set at $5.0 \%$ for all analyses, calculated using the chi-square test or the Mann-Whitney $U$ test. Statistical analyses were conducted using SAS version 9.4 (SAS Institute Inc, Cary, NC, USA) by SRL Medisearch Co, Ltd, Tokyo, Japan.

\section{Results}

\section{Participants}

A total of 10000 survey responses were received, of which 5023 were from males and 4977 from females; participants' background details are shown in Supplementary Table 1. By age group, 804 males and 762 females were in their 20s, 952 and 927, respectively, were in their 30s, 1197 and 1168 were in their 40s, 988 and 983 were in their 50s, and 1082 and 1137 were in their 60s. The most frequently reported complications were hypertension $(\mathrm{n}=1187)$, hyperlipidemia ( $\mathrm{n}=702)$, gastroduodenal ulcer $(\mathrm{n}=597)$, hemorrhoidal disease $(n=455)$, and diabetes mellitus $(n=435) ; 7182$ participants had no complications to report. 


\section{Primary Endpoint}

The numbers of participants with diagnoses of constipation and GERD by various criteria are shown in Table 1 . According to the Rome IV diagnostic criteria, functional constipation was observed in 439 participants; chronic constipation, according to the Japanese guidelines, in 3804 participants; and subjective symptoms of constipation in 2563 participants. The numbers of participants with broad-sense GERD1, broad-sense GERD2, and narrow-sense GERD were 2785, 1013, and 1223, respectively. The number of participants with broad-sense GERD2 was smaller than that with narrow-sense GERD, which was unexpected, as broad-sense GERD2 criteria are less strict. Investigation of the reason for this result found that participants with narrow-sense GERD scored highly on questions \#3 and \#4 of the GerdQ (Supplementary Table 2); as a result, many participants were able to meet the criteria for narrow-sense GERD (GerdQ score $\geq 8$ ) even if they did not meet the criteria for broad-sense GERD2.

The proportions of participants with each symptom of chronic constipation are shown in Table 2. Some participants were not aware of having constipation but, nonetheless, met the criteria for having chronic constipation according to the Japanese guidelines (Supplementary Table 3). Thus, the number of participants having chronic constipation was higher than the number who were aware of having constipation. The most commonly reported symptoms of chronic constipation were straining, lumpy or hard stools, sensation

Table 1. Numbers of Participants With Constipation and Gastroesophageal Reflux Disease According to Diagnostic Criteria

\begin{tabular}{|c|c|c|c|c|c|c|c|c|c|}
\hline \multirow[b]{2}{*}{ Constipation status } & \multicolumn{3}{|c|}{ Broad-sense GERD1 } & \multicolumn{3}{|c|}{ Broad-sense GERD2 } & \multicolumn{3}{|c|}{ Narrow-sense GERD } \\
\hline & $\begin{array}{c}\text { With } \\
\text { GERD }\end{array}$ & $\begin{array}{l}\text { Without } \\
\text { GERD }\end{array}$ & Total & $\begin{array}{c}\text { With } \\
\text { GERD }\end{array}$ & $\begin{array}{l}\text { Without } \\
\text { GERD }\end{array}$ & Total & $\begin{array}{c}\text { With } \\
\text { GERD }\end{array}$ & $\begin{array}{l}\text { Without } \\
\text { GERD }\end{array}$ & Total \\
\hline \multicolumn{10}{|l|}{ Functional constipation $^{\mathrm{a}}$} \\
\hline With constipation & $170(6.1)$ & $269(3.7)$ & 439 & $73(7.2)$ & $366(4.1)$ & 439 & $77(6.3)$ & $362(4.1)$ & 439 \\
\hline Without constipation & $2615(93.9)$ & $6946(96.3)$ & 9561 & $940(92.8)$ & $8621(95.9)$ & 9561 & $1146(93.7)$ & $8415(95.9)$ & 9561 \\
\hline Total & 2785 & 7215 & 10000 & 1013 & 8987 & 10000 & 1223 & 8777 & 10000 \\
\hline \multicolumn{10}{|l|}{ Chronic constipation $^{\mathrm{b}}$} \\
\hline With constipation & $1533(55.0)$ & $2271(31.5)$ & 3804 & $596(58.8)$ & $3208(35.7)$ & 3804 & $693(56.7)$ & $3111(35.4)$ & 3804 \\
\hline Without constipation & $1252(45.0)$ & $4944(68.5)$ & 6196 & $417(41.2)$ & $5779(64.3)$ & 6196 & $530(43.3)$ & $5666(64.6)$ & 6196 \\
\hline Total & 2785 & 7215 & 10000 & 1013 & 8987 & 10000 & 1223 & 8777 & 10000 \\
\hline \multicolumn{10}{|l|}{ Awareness of constipation } \\
\hline With constipation & $1004(36.1)$ & $1559(21.6)$ & 2563 & $419(41.4)$ & $2144(23.9)$ & 2563 & $475(38.8)$ & $2088(23.8)$ & 2563 \\
\hline Without constipation & $1781(63.9)$ & $5656(78.4)$ & 7437 & $594(58.6)$ & $6843(76.1)$ & 7437 & 748 (61.2) & $6689(76.2)$ & 7437 \\
\hline Total & 2785 & 7215 & 10000 & 1013 & 8987 & 10000 & 1223 & 8777 & 10000 \\
\hline
\end{tabular}

${ }^{a}$ According to Rome IV diagnostic criteria.

${ }^{\mathrm{b}}$ According to Japanese guidelines.

GERD, gastroesophageal reflux disease.

Values are presented as $\mathrm{n}(\%)$ or $\mathrm{n}$.

Table 2. Responses to Diagnostic Criteria for Functional Constipation (Adapted from Lacy et $\mathrm{al}^{14}$ )

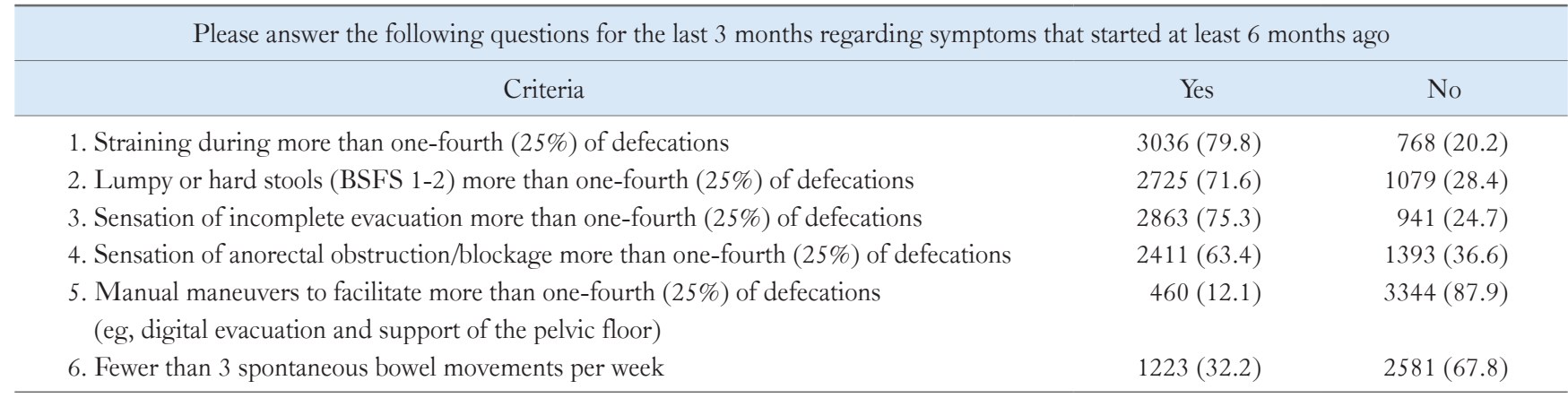

BSFS, Bristol stool form scale.

Values are presented as $\mathrm{n}(\%)$. 
Table 3. Likelihood of Participants With Gastroesophageal Reflux Disease Being Constipated

\begin{tabular}{|c|c|c|c|c|c|c|c|c|c|}
\hline \multirow[b]{2}{*}{ Constipation status } & \multicolumn{3}{|c|}{ Broad-sense GERD1 } & \multicolumn{3}{|c|}{ Broad-sense GERD2 } & \multicolumn{3}{|c|}{ Narrow-sense GERD } \\
\hline & $\begin{array}{c}\text { OR } \\
{[95 \% \mathrm{CI}]}\end{array}$ & $\chi^{2}$ & $P$-value & $\begin{array}{c}\text { OR } \\
{[95 \% \mathrm{CI}]}\end{array}$ & $\chi^{2}$ & $P$-value & $\begin{array}{c}\text { OR } \\
{[95 \% \mathrm{CI}]}\end{array}$ & $\chi^{2}$ & $P$-value \\
\hline Functional constipation $^{\mathrm{a}}$ & $\begin{array}{c}1.68 \\
{[1.38,2.04]}\end{array}$ & 27.02 & $<0.001$ & $\begin{array}{c}1.83 \\
{[1.41,2.37]}\end{array}$ & 21.30 & $<0.001$ & $\begin{array}{c}1.56 \\
{[1.21,2.01]}\end{array}$ & 12.06 & 0.001 \\
\hline Chronic constipation $^{\mathrm{b}}$ & $\begin{array}{c}2.67 \\
{[2.44,2.92]}\end{array}$ & 473.57 & $<0.001$ & {$[2.26,2.94]$} & 206.81 & $<0.001$ & $\begin{array}{c}2.38 \\
{[2.11,2.69]}\end{array}$ & 205.06 & $<0.001$ \\
\hline Awareness of constipation & $\begin{array}{c}2.05 \\
{[1.86,2.25]}\end{array}$ & 219.89 & $<0.001$ & $\begin{array}{c}2.25 \\
{[1.97,2.57]}\end{array}$ & 146.36 & $<0.001$ & $\begin{array}{c}2.03 \\
{[1.80,2.31]}\end{array}$ & 127.55 & $<0.001$ \\
\hline
\end{tabular}

${ }^{a}$ According to Rome IV diagnostic criteria.

${ }^{\mathrm{b}}$ According to Japanese guidelines.

GERD, gastroesophageal reflux disease.

All results have a degree of freedom of 1 . ORs are for the presence of constipation in participants with GERD compared with those without GERD.

of incomplete evacuation, and sensation of anorectal obstruction/ blockage.

Notably, the number of participants with constipation/GERD overlap varied according to the definitions used, from 73 (7.2\% of all participants with GERD) when Rome IV and broad-sense GERD2 were applied to 1533 (55.0\% of all participants with GERD) when the chronic constipation guidelines and broad-sense GERD1 were applied. By comparison, the number of participants with constipation but no GERD ranged from 269 (3.7\% of all participants without GERD) by broad-sense GERD1 and Rome IV criteria to 3208 (35.7\% of all participants without GERD) by broad-sense GERD2 and chronic constipation guidelines (Table 1). For all participants with GERD, regardless of the definition used, the odds of being constipated were significantly higher than for participants without GERD: the OR $(95 \% \mathrm{CI})$ for being constipated between these groups ranged from $1.56(1.21,2.01)$ for the combination of narrow-sense GERD and Rome IV criteria to 2.67 (2.44, 2.92) for the combination of broad-sense GERD1 and chronic constipation criteria. These ORs were significant for all combinations of definitions used (all $P \leq 0.001$; chi-square tests) (Table 3).

\section{Secondary Endpoints}

Four groups of participants were used to analyze the relationships between narrow-sense GERD (GerdQ score $\geq 8$ ) and chronic constipation (by the chronic constipation guideline): constipation plus GERD (Group A), constipation alone (Group B), GERD alone (Group C), and neither (Group D).

\section{Demographic and Clinical Factors}

Background factors were compared among the 4 groups (Table 4). The proportion of females was highest in Group B (constipa- tion), and the proportion of males was highest in Group C (GERD). The male-to-female ratio was nearly equal in Group A (the overlap group). In groups $A$ and $B$, participants tended to be younger, with lower proportions in the $\geq 50$ years to $<60$ years and $\geq 60$ years categories. Weight and body mass index were slightly higher in Group C compared with the other groups. Hypertension, diabetes mellitus, hyperlipidemia, gastroduodenal ulceration, and hemorrhoidal diseases were all common underlying complications in our survey participants, and all were found at a higher frequency in Group C and Group A (ie, associated with GERD). Logistic regression analysis, using presence of GERD as the dependent variable, revealed ORs (95\% CIs) for an association of GERD with each complication of $1.42(1.19,1.69)$ for hypertension, 1.48 $(1.15,1.91)$ for diabetes, $1.45(1.18,1.79)$ for hyperlipidemia, 2.13 $(1.74,2.61)$ for gastroduodenal ulcer, and $1.89(1.49,2.38)$ for hemorrhoidal disease; these ORs were significant (hypertension, $P<0.001$; diabetes, $P=0.003$; hyperlipidemia, $P=0.001$; gastroduodenal ulcer, $P<0.001$; hemorrhoidal disease, $P<0.001$; multivariate logistic regression tests).

There were no clear differences in the frequency of constipation or GERD overlap by place of residence, occupation, annual household income, or highest educational attainment (Supplementary Table 4).

\section{Eight-item Short Form Health Survey Questionnaire}

For the SF-8 (Supplementary Table 5), all subscales were reduced in Groups B and C compared with Group D (MannWhitney $U$ test for B:D and C:D, both $P<0.001)$. The scores in Group A were the lowest of all 4 groups (Mann-Whitney $U$ test for A:B and A:C, both $P<0.001)$. The subscales for bodily pain, general health perception, and mental health were the most affected 
Table 4. Participants' Characteristics According to the Presence of Chronic Constipation and Narrow-sense Gastroesophageal Reflux Disease

\begin{tabular}{|c|c|c|c|c|c|}
\hline \multirow[b]{2}{*}{ Characteristics } & \multicolumn{5}{|c|}{ Chronic constipation guidelines/narrow-sense GERD } \\
\hline & $\begin{array}{c}\text { Group A: } \\
\text { constipation and } \\
\text { GERD } \\
(\mathrm{n}=693)\end{array}$ & $\begin{array}{c}\text { Group B: } \\
\text { constipation only } \\
(\mathrm{n}=3111)\end{array}$ & $\begin{array}{l}\text { Group C: } \\
\text { GERD only } \\
(\mathrm{n}=530)\end{array}$ & $\begin{array}{c}\text { Group D: } \\
\text { no constipation, } \\
\text { no GERD } \\
(\mathrm{n}=5666)\end{array}$ & $\begin{array}{c}\text { Total } \\
(\mathrm{N}=10000)\end{array}$ \\
\hline \multicolumn{6}{|l|}{ Sex } \\
\hline Male & $348(50.2)$ & $1246(40.1)$ & $315(59.4)$ & $3114(55.0)$ & 5023 \\
\hline Female & $345(49.8)$ & $1865(59.9)$ & $215(40.6)$ & $2552(45.0)$ & 4977 \\
\hline Age (yr) & $43.8 \pm 13.2$ & $44.4 \pm 13.6$ & $47.9 \pm 12.1$ & $47.1 \pm 13.2$ & $46.0 \pm 13.4$ \\
\hline$\geq 20$ and $<30$ & $131(18.9)$ & $603(19.4)$ & $56(10.6)$ & $776(13.7)$ & 1566 \\
\hline$\geq 30$ and $<40$ & $148(21.4)$ & $658(21.2)$ & $85(16.0)$ & $988(17.4)$ & 1879 \\
\hline$\geq 40$ and $<50$ & $172(24.8)$ & $679(21.8)$ & $143(27.0)$ & $1371(24.2)$ & 2365 \\
\hline$\geq 50$ and $<60$ & $122(17.6)$ & $550(17.7)$ & $131(24.7)$ & $1168(20.6)$ & 1971 \\
\hline$\geq 60$ and $<70$ & $120(17.3)$ & $621(20.0)$ & $115(21.7)$ & $1363(24.1)$ & 2219 \\
\hline Height $(\mathrm{cm})^{\mathrm{a}}$ & $164.8 \pm 8.3$ & $163.3 \pm 8.4$ & $165.5 \pm 8.7$ & $165.1 \pm 8.5$ & $164.6 \pm 8.5$ \\
\hline Weight $(\mathrm{kg})^{\mathrm{a}}$ & $61.5 \pm 12.9$ & $58.9 \pm 12.2$ & $65.5 \pm 14.2$ & $61.4 \pm 12.3$ & $60.9 \pm 12.5$ \\
\hline Body mass index $\left(\mathrm{kg} / \mathrm{m}^{2}\right)$ & $22.5 \pm 3.7$ & $22.0 \pm 3.5$ & $23.7 \pm 3.8$ & $22.4 \pm 3.4$ & $22.3 \pm 3.5$ \\
\hline \multicolumn{6}{|l|}{ Complications } \\
\hline Hypertension & $123(17.7)$ & $316(10.2)$ & $110(20.8)$ & $638(11.3)$ & 1187 \\
\hline Diabetes mellitus & $56(8.1)$ & $126(4.1)$ & $40(7.5)$ & $213(3.8)$ & 435 \\
\hline Hyperlipidemia & $80(11.5)$ & $227(7.3)$ & $72(13.6)$ & $323(5.7)$ & 702 \\
\hline Gastroduodenal ulcers & $94(13.6)$ & $200(6.4)$ & $57(10.8)$ & $246(4.3)$ & 597 \\
\hline Hemorrhoidal disease & $71(10.2)$ & $155(5.0)$ & $43(8.1)$ & $186(3.3)$ & 455 \\
\hline Diverticulosis & $6(0.9)$ & $32(1.0)$ & $7(1.3)$ & $23(0.4)$ & 68 \\
\hline Other cancers & $2(0.3)$ & $41(1.3)$ & $7(1.3)$ & $31(0.5)$ & 81 \\
\hline Cerebrovascular and neurological diseases & $18(2.6)$ & $49(1.6)$ & $7(1.3)$ & $32(0.6)$ & 106 \\
\hline Chronic obstructive pulmonary disease & $1(0.1)$ & $6(0.2)$ & $0(0.0)$ & $4(0.1)$ & 11 \\
\hline Liver disease & $28(4.0)$ & $35(1.1)$ & $18(3.4)$ & $69(1.2)$ & 150 \\
\hline Kidney disease & $18(2.6)$ & $58(1.9)$ & $9(1.7)$ & $61(1.1)$ & 146 \\
\hline Other & $28(4.0)$ & $78(2.5)$ & $20(3.8)$ & $119(2.1)$ & 245 \\
\hline None & $371(53.5)$ & $2221(71.4)$ & $305(57.5)$ & $4285(75.6)$ & 7182 \\
\hline
\end{tabular}

${ }^{a}$ Includes $0.3 \%$ overall outlier removal to exclude obvious data entry errors. GERD, gastroesophageal reflux disease.

Values are presented as $\mathrm{n}(\%)$ or mean $\pm \mathrm{SD}$.

in Group A (scores of 46.0, 46.4, and 45.0, respectively). The mental component summary score in this group was 44.9 (compared with 50.4 in Group D). Data were also summarized visually (Fig. 1).

\section{Gastrointestinal Symptom Rating Scale}

For the GSRS (Supplementary Table 5), Groups A-C had worse symptoms than Group D, indicating deterioration of QOL, with Group A being most impacted (Mann-Whitney $U$ test for A:B, A:C, B:D, and C:D, all $P<0.001$, for all items). Data were also summarized visually (Fig. 2).

\section{Bristol Stool Form Scale}

Groups were compared using stool classifications of abnormal (BSFS 1, 2, 6, and 7) and normal (BSFS 3, 4, and 5; Table 5). Groups B and C had a higher frequency of abnormal stools compared with Group D (chi-square test for B:D and C:D, both $P<$ 0.001). In turn, the frequency of abnormal stools in Group A was higher than in Groups B or C (chi-square test for A:B and A:C, both $P<0.001)$.

\section{Constipation Scoring System}

Compared with Group D, the CSS total score was increased 


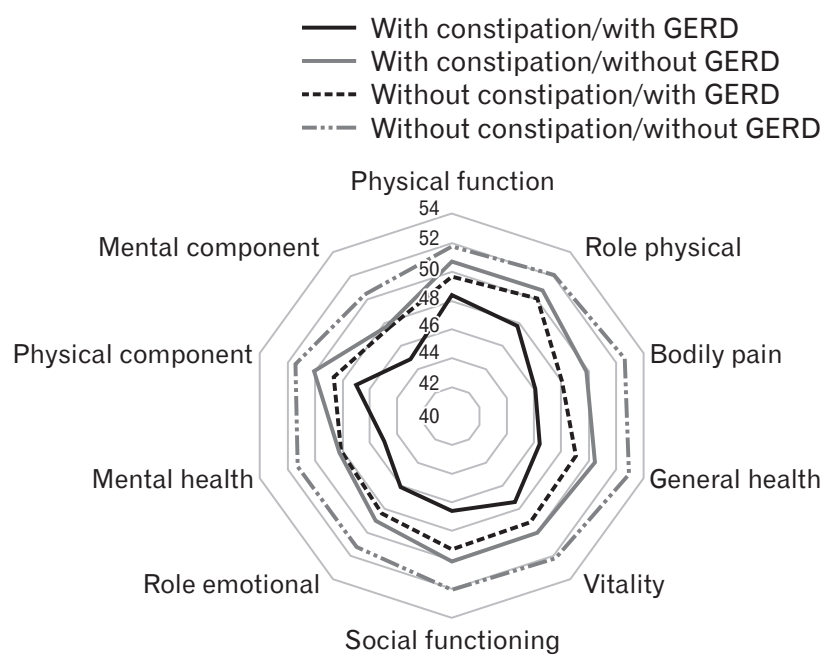

Figure 1. Eight-item Short Form Health Survey Questionnaire according to the presence of chronic constipation and the presence of narrow-sense gastroesophageal reflux disease (GERD).

in Groups A-C, with the greatest increase reported in Group A (Mann-Whitney $U$ test for A:B, A:C, B:D, and C:D, all $P<$ 0.001; Table 5).

\section{Satisfaction with Bowel Movements}

Compared with Group D, satisfaction was decreased in Groups A-C, with the greatest decrease reported in Group A (chi-square test for satisfied vs dissatisfied in A:B, A:C, B:D, and C:D, all $P<$ 0.001; Table 5).

\section{Medication Usage}

Gastric medication use, gastric medication type, constipation medication use, and constipation medication type were compared between groups (Table 6 and Supplementary Table 6). In Group A, $52.4 \%$ used gastric medication, and $26.0 \%$ used constipation medication. In this group, $40.4 \%$ did not use either gastric or constipation medications. Proton pump inhibitors (PPIs) or potassium ion-competitive acid blockers (PCABs) were prescribed to 216 participants with GERD (Groups A and C) and 336 participants without GERD (Groups B and D) (Supplementary Table 7). Of these, the number of participants using drug treatment for constipation was 71 and 82 , respectively, resulting in usage rates of $32.9 \%$ and $24.4 \%$.

The concomitant use of gastric and constipation drugs is described in Supplementary Table 6. Among the constipation drugs used, stimulant laxatives were the most commonly used, followed by saline laxatives; combined use of saline laxatives with PPI (an acid

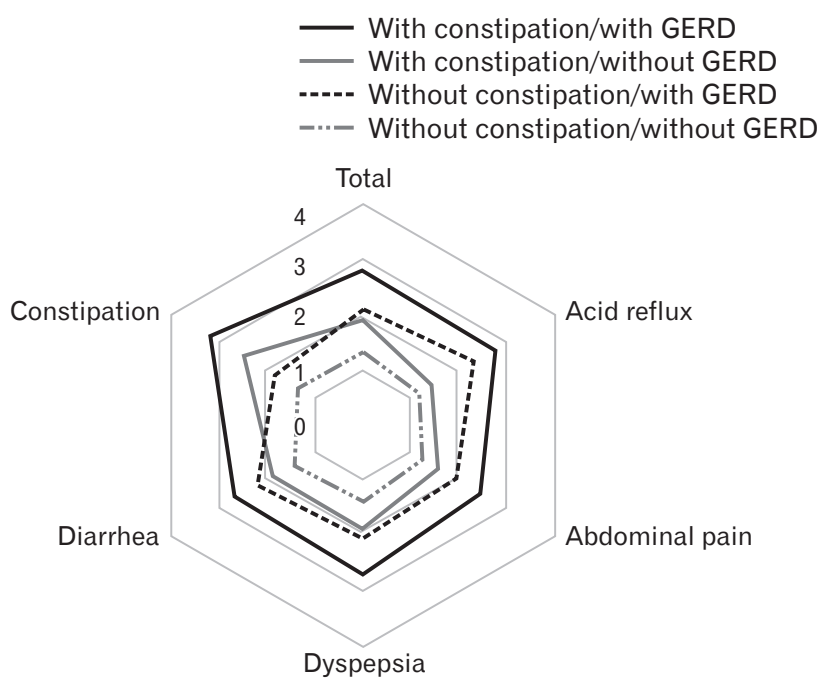

Figure 2. Gastrointestinal Symptom Rating Scale according to the presence of chronic constipation and the presence of narrow-sense gastroesophageal reflux disease (GERD).

secretion depressant) was reported in 23 participants, combined use with $\mathrm{PCAB}$ in 10, and combined use with histamine $\mathrm{H} 2$ receptor blockers in 28 .

\section{Frequency Scale for the Symptoms of Gastroesopha- geal Reflux Disease}

The data for the FSSG scale, which investigated the severity of GERD symptoms, are shown in Table 5. Compared with Group $\mathrm{D}$, the total score, reflux score, and dysmotility score were increased in Groups A-C, with the greatest increase reported in Group A (Mann-Whitney $U$ test for A:B, A:C, B:D, and C:D, all $P<$ 0.001 , for all items).

Using a total FSSG score of $\geq 8$ as the definition of GERD, the relationship between GERD and chronic constipation was investigated. Among 2813 participants with GERD, 1734 (61.6\%) had chronic constipation, and 1079 (38.4\%) did not have chronic constipation. Of the 7187 participants without GERD, 2070 (28.8\%) had chronic constipation, and 5117 (71.2\%) did not have chronic constipation. The OR for having chronic constipation was significantly higher among participants with GERD (3.97, 95\% CI $[3.63,4.35]$ ) (Supplementary Table 8). Logistic regression was performed to examine the OR of becoming constipated in terms of the 2 categorical scores on the FSSG scale (Table 7). Both subscales were significant in the univariate and multivariate analyses; however, the multivariate analysis demonstrated a higher association with dysmotility symptoms $(\mathrm{OR}, 1.26$; $95 \% \mathrm{CI}[1.23,1.28])$ than reflux symptoms (OR, 1.02; 95\% CI [1.00, 1.04]). 
Table 5. Frequency Scale for the Symptoms of Gastroesophageal Reflux Disease, Bristol Stool Form Scale, and Constipation Scoring System Scores, and Satisfaction With Bowel Movements According to the Presence of Chronic Constipation and the Presence of Narrow-sense Gastroesophageal Reflux Disease

\begin{tabular}{|c|c|c|c|c|c|}
\hline \multirow[b]{2}{*}{ Survey } & \multicolumn{5}{|c|}{ Chronic constipation guidelines/narrow-sense GERD } \\
\hline & $\begin{array}{c}\text { Group A: } \\
\text { constipation and } \\
\text { GERD } \\
(\mathrm{n}=693)\end{array}$ & $\begin{array}{c}\text { Group B: } \\
\text { constipation only } \\
(\mathrm{n}=3111)\end{array}$ & $\begin{array}{l}\text { Group C: } \\
\text { GERD only } \\
(\mathrm{n}=530)\end{array}$ & $\begin{array}{c}\text { Group D: } \\
\text { no constipation, } \\
\text { no GERD } \\
(\mathrm{n}=5666)\end{array}$ & $\begin{array}{c}\text { Total } \\
(\mathrm{N}=10000)\end{array}$ \\
\hline \multicolumn{6}{|l|}{ FSSG score } \\
\hline Total & $15.8 \pm 8.9$ & $6.9 \pm 6.1$ & $10.8 \pm 8.4$ & $3.2 \pm 4.3$ & $5.7 \pm 6.6$ \\
\hline Reflux score & $8.5 \pm 5.4$ & $2.7 \pm 3.3$ & $6.0 \pm 5.1$ & $1.3 \pm 2.2$ & $2.5 \pm 3.7$ \\
\hline Dysmotility score & $7.4 \pm 4.3$ & $4.2 \pm 3.5$ & $4.7 \pm 4.0$ & $1.9 \pm 2.5$ & $3.2 \pm 3.5$ \\
\hline \multicolumn{6}{|l|}{ BSFS score } \\
\hline BSFS-1 & $74(10.7)$ & $286(9.2)$ & $15(2.8)$ & $65(1.1)$ & 440 \\
\hline BSFS-2 & $121(17.5)$ & $359(11.5)$ & $11(2.1)$ & $75(1.3)$ & 566 \\
\hline BSFS-3 & $184(26.6)$ & $832(26.7)$ & $32(6.0)$ & $378(6.7)$ & 1426 \\
\hline BSFS-4 & $181(26.1)$ & $1160(37.3)$ & $319(60.2)$ & $4198(74.1)$ & 5858 \\
\hline BSFS-5 & $73(10.5)$ & $335(10.8)$ & $99(18.7)$ & $693(12.2)$ & 1200 \\
\hline BSFS-6 & $54(7.8)$ & $107(3.4)$ & $47(8.9)$ & $211(3.7)$ & 419 \\
\hline BSFS-7 & $6(0.9)$ & $32(1.0)$ & $7(1.3)$ & $46(0.8)$ & 91 \\
\hline BSFS-3/4/5 & $438(63.2)$ & $2327(74.8)$ & $450(84.9)$ & $5269(93.0)$ & 8484 \\
\hline BSFS-1/2/6/7 & $255(36.8)$ & $784(25.2)$ & $80(15.1)$ & $397(7.0)$ & 1516 \\
\hline CSS score & $8.4 \pm 4.6$ & $6.6 \pm 4.0$ & $3.6 \pm 3.7$ & $2.3 \pm 2.7$ & $4.1 \pm 4.0$ \\
\hline Frequency of bowel movements & $0.5 \pm 0.9$ & $0.3 \pm 0.7$ & $0.2 \pm 0.8$ & $0.2 \pm 0.6$ & $0.2 \pm 0.7$ \\
\hline Painful evacuation effort & $1.4 \pm 1.0$ & $1.2 \pm 0.9$ & $0.5 \pm 0.8$ & $0.4 \pm 0.6$ & $0.7 \pm 0.9$ \\
\hline Feeling Incomplete evacuation & $1.8 \pm 1.0$ & $1.4 \pm 0.9$ & $0.8 \pm 0.9$ & $0.5 \pm 0.7$ & $0.9 \pm 0.9$ \\
\hline Abdominal pain & $1.4 \pm 0.9$ & $1.1 \pm 0.8$ & $0.9 \pm 0.8$ & $0.6 \pm 0.7$ & $0.8 \pm 0.8$ \\
\hline Minutes in lavatory per attempt & $1.0 \pm 0.9$ & $0.8 \pm 0.8$ & $0.5 \pm 0.7$ & $0.4 \pm 0.6$ & $0.5 \pm 0.7$ \\
\hline Type of assistance (none/laxative/digital) & $0.3 \pm 0.5$ & $0.1 \pm 0.4$ & $0.1 \pm 0.3$ & $0.0 \pm 0.2$ & $0.1 \pm 0.3$ \\
\hline Unsuccessful attempts at evacuation per $24 \mathrm{hr}$ & $0.7 \pm 0.7$ & $0.5 \pm 0.6$ & $0.3 \pm 0.5$ & $0.1 \pm 0.4$ & $0.3 \pm 0.5$ \\
\hline Duration of constipation (yr) & $1.3 \pm 1.4$ & $1.2 \pm 1.5$ & $0.3 \pm 0.9$ & $0.2 \pm 0.7$ & $0.6 \pm 1.2$ \\
\hline \multicolumn{6}{|l|}{ Satisfaction with bowel movements } \\
\hline Very satisfied & $18(2.6)$ & $117(3.8)$ & $88(16.6)$ & $1389(24.5)$ & 1612 \\
\hline Satisfied & $169(24.4)$ & $1000(32.1)$ & $240(45.3)$ & $2941(51.9)$ & 4350 \\
\hline Neither satisfied nor unsatisfied & $169(24.4)$ & $800(25.7)$ & $126(23.8)$ & $893(15.8)$ & 1988 \\
\hline Unsatisfied & $221(31.9)$ & $839(27.0)$ & $54(10.2)$ & $298(5.3)$ & 1412 \\
\hline Very unsatisfied & $116(16.7)$ & $355(11.4)$ & $22(4.2)$ & $145(2.6)$ & 638 \\
\hline \multicolumn{6}{|l|}{ Satisfaction category } \\
\hline Satisfactory (very satisfied + satisfied) & $187(27.0)$ & $1117(35.9)$ & $328(61.9)$ & $4330(76.4)$ & 5962 \\
\hline $\begin{array}{l}\text { Unsatisfactory (Neither satisfied nor unsatisfied } \\
+ \text { unsatisfied }+ \text { very unsatisfied) }\end{array}$ & $506(73.0)$ & $1994(64.1)$ & $202(38.1)$ & $1336(23.6)$ & 4038 \\
\hline
\end{tabular}

GERD, gastroesophageal reflux disease; FSSG, Frequency Scale for the Symptoms of GERD; BSFS, Bristol Stool Form Scale; CSS, constipation scoring system. Values are presented as mean $\pm \mathrm{SD}$ or $\mathrm{n}(\%)$.

\section{Discussion}

The REACTION-J2 study was an internet survey conducted to investigate the proportion of Japanese individuals with overlap- ping constipation and GERD, and their health status and management. Although prior studies had noted the presence of overlapping symptoms of constipation and GERD across different races and ethnicities, ${ }^{8,9}$ this is the first real-world survey to examine this overlap in individuals in Japan. Notably, awareness of constipation 
Table 6. Use or Non-use of Gastric Medication Depending on the Presence or Absence of Chronic Constipation, Presence or Absence of Narrow Gastroesophageal Reflux Disease, Type of Gastric Medication, Use or Non-use of Constipation Agent, and Type of Constipation Agent

\begin{tabular}{|c|c|c|c|c|c|}
\hline \multirow[b]{2}{*}{ Medication use } & \multicolumn{5}{|c|}{ Chronic constipation guidelines/narrow-sense GERD } \\
\hline & $\begin{array}{c}\text { Group A: } \\
\text { constipation and } \\
\text { GERD } \\
(\mathrm{n}=693)\end{array}$ & $\begin{array}{c}\text { Group B: } \\
\text { constipation only } \\
(\mathrm{n}=3111)\end{array}$ & $\begin{array}{l}\text { Group C: } \\
\text { GERD only } \\
(\mathrm{n}=530)\end{array}$ & $\begin{array}{c}\text { Group D: } \\
\text { no constipation, } \\
\text { no GERD } \\
(\mathrm{n}=5666)\end{array}$ & $\begin{array}{c}\text { Total } \\
(\mathrm{N}=10000)\end{array}$ \\
\hline \multicolumn{6}{|l|}{ Use of gastric medication } \\
\hline Yes & $363(52.4)$ & $538(17.3)$ & $223(42.1)$ & $608(10.7)$ & 1732 \\
\hline No & $330(47.6)$ & $2573(82.7)$ & $307(57.9)$ & $5058(89.3)$ & 8268 \\
\hline \multicolumn{6}{|l|}{ Type of gastric medication } \\
\hline PPI & $119(17.2)$ & $139(4.5)$ & $63(11.9)$ & $121(2.1)$ & 442 \\
\hline PCAB & $35(5.1)$ & $53(1.7)$ & $20(3.8)$ & $45(0.8)$ & 153 \\
\hline Histamine $\mathrm{H} 2$ receptor blocker & $133(19.2)$ & $134(4.3)$ & $69(13.0)$ & $166(2.9)$ & 502 \\
\hline Prokinetic agent & $35(5.1)$ & $41(1.3)$ & $19(3.6)$ & $30(0.5)$ & 125 \\
\hline Herbal drug & $68(9.8)$ & $76(2.4)$ & $21(4.0)$ & $104(1.8)$ & 269 \\
\hline Other & $32(4.6)$ & $84(2.7)$ & $52(9.8)$ & $115(2.0)$ & 283 \\
\hline Unknown, oral & $57(8.2)$ & $105(3.4)$ & $30(5.7)$ & $122(2.2)$ & 314 \\
\hline \multicolumn{6}{|l|}{ Use of constipation medication } \\
\hline Yes & $180(26.0)$ & $487(15.7)$ & $37(7.0)$ & $165(2.9)$ & 869 \\
\hline No & $513(74.0)$ & $2624(84.3)$ & $493(93.0)$ & $5501(97.1)$ & 9131 \\
\hline \multicolumn{6}{|l|}{ Type of constipation medication } \\
\hline Stimulant laxatives & $104(57.8)$ & $244(50.1)$ & $12(32.4)$ & $53(32.1)$ & 413 \\
\hline Enemas and suppositories & $27(15.0)$ & $50(10.3)$ & $4(10.8)$ & $12(7.3)$ & 93 \\
\hline Saline laxatives & $39(21.7)$ & $133(27.3)$ & $6(16.2)$ & $34(20.6)$ & 212 \\
\hline Osmotic laxatives & $2(1.1)$ & $4(0.8)$ & $0(0.0)$ & $1(0.6)$ & 7 \\
\hline Inflatable laxatives & $0(0.0)$ & $5(1.0)$ & $0(0.0)$ & $2(1.2)$ & 7 \\
\hline $\begin{array}{l}\text { Chloride channel activator/guanylate cyclase } \\
\mathrm{C} \text { agonists/bile acid ileal transporter inhibitor }\end{array}$ & $1(0.6)$ & $5(1.0)$ & $1(2.7)$ & $1(0.6)$ & 8 \\
\hline PEG & $3(1.7)$ & $2(0.4)$ & $0(0.0)$ & $2(1.2)$ & 7 \\
\hline Other & $14(7.8)$ & $49(10.1)$ & $8(21.6)$ & $22(13.3)$ & 93 \\
\hline Unknown & $18(10.0)$ & $64(13.1)$ & $10(27.0)$ & $44(26.7)$ & 136 \\
\hline \multicolumn{6}{|l|}{ Medication use } \\
\hline Constipation and gastric medication & $130(18.8)$ & $139(4.5)$ & $27(5.1)$ & $47(0.8)$ & 343 \\
\hline Constipation medication only & $50(7.2)$ & $348(11.2)$ & $10(1.9)$ & $118(2.1)$ & 526 \\
\hline Gastric medication only & $233(33.6)$ & $399(12.8)$ & $196(37.0)$ & $561(9.9)$ & 1389 \\
\hline None & $280(40.4)$ & $2225(71.5)$ & $297(56.0)$ & $4940(87.2)$ & 7742 \\
\hline
\end{tabular}

GERD, gastroesophageal reflux disease; PPI, proton pump inhibitor; PCAB, potassium ion-competitive acid blocker; PEG, polyethylene glycol.

Values are presented as $\mathrm{n}(\%)$.

Table 7. Logistic Regression Analysis for Each Subscale Score of Frequency Scale for the Symptoms of Gastroesophageal Reflux Disease During Chronic Constipation

\begin{tabular}{|c|c|c|c|c|}
\hline \multirow{2}{*}{ Score } & \multicolumn{2}{|c|}{ Univariate } & \multicolumn{2}{|c|}{ Multivariate } \\
\hline & OR $[95 \% \mathrm{CI}]$ & $P$-value & OR $[95 \% \mathrm{CI}]$ & $P$-value \\
\hline Reflux score & $1.18[1.16,1.19]$ & $<0.001$ & $1.02[1.00,1.04]$ & 0.026 \\
\hline Dysmotility score & $1.27[1.26,1.29]$ & $<0.001$ & $1.26[1.23,1.28]$ & $<0.001$ \\
\hline
\end{tabular}


in this survey (25.6\%) was only half of that reported in the previous REACTION-J survey (51.5\%). ${ }^{5}$ One possible reason for this discrepancy was that the description of the prior REACTIONJ survey specifically noted constipation in the title when recruiting participants, which may have led to the participation of individuals with a particular interest in the condition.

A previous United States study reported that $28.3 \%$ of patients with GERD had constipation. ${ }^{11}$ While the overall proportion varied in the current study (from $6.1 \%$ to $58.8 \%$ ) depending on the definitions used, the proportion of individuals meeting each definition of GERD was similar within each definition of constipation (eg, when Rome IV criteria were used for constipation, the proportion of participants with GERD [broad-sense GERD1, broad-sense GERD2, or narrow-sense GERD] was found to be within a narrow range of $6.1 \%$ and $7.2 \%$; Table 1 ).

According to the Rome IV diagnostic criteria, the number of participants with functional constipation was significantly lower than that determined using the Japanese clinical practice guidelines. This was because of the participants who met Japanese guidelines for chronic constipation ( $\mathrm{n}=3804$; Supplementary Table 3), many ( $\mathrm{n}=3044)$ answered "yes" to the question "Do you have soft stools without the use of constipation medicine/laxatives?" and were judged not to have constipation by Rome IV criteria, which state that "soft stools are rarely present without the use of laxatives." ${ }^{14} \mathrm{We}$ consider that survey participants may not have correctly understood the meaning of the term 'soft stools.' In general, stool consistency may vary during the process of defecation. Thus, it is possible to present hard stools at the start of defecation, followed by soft stools at the middle or end of defecation. Therefore, many participants may have frequently reported an overall status of soft stools. The number of participants diagnosed using the clinical practice guidelines for chronic constipation $(\mathrm{n}=3804$; Supplementary Table 3) was also higher than the number who reported subjective symptoms ( $n=2563$; Supplementary Table 3). This is likely because multiple factors are involved in diagnosing constipation (our study showed a high proportion of straining, hard stools, and residual stool sensation), whereas inquiring only about defecation frequency is insufficient to identify chronic constipation.

The calculation of ORs found that all definitions of GERD using the GerdQ were associated with higher rates of constipation (1.56 to 2.67-fold likelihood; Table 3). In the secondary assessments, an FSSG score of $\geq 8$ points was used to define GERD, resulting in an OR for chronic constipation of 3.97 (Supplementary Table 8). The differences in OR between the 2 scales may be related to the inclusion of dysmotility-like dyspeptic symptoms in the
FSSG scale, as shown by logistic regression analysis. From this, we can conclude that when diagnosing GERD using the FSSG scale, patients reporting dysmotility-like dyspeptic symptoms may be suspected of having concomitant chronic constipation.

In the analysis of groups A-D, participants with overlapping constipation and GERD showed worse QOL (SF-8 and GSRS) and worse symptoms (GERD: FSSG scale; constipation: BSFS, CSS, and satisfaction with bowel movement) compared with either condition alone. As $40.4 \%$ of participants in Group A were not receiving gastric or constipation medications (Table 6), improving treatment for these participants may be effective in improving symptoms and QOL.

High proportions of stimulant laxatives and saline laxatives were prescribed to participants. Other medication types, such as chloride channel activators, guanylate cyclase $\mathrm{C}$ agonists, ileal bile acid transporter inhibitors, and polyethylene glycol-based agents, were only recently launched in Japan for chronic constipation, which accounts for the limited rates of use in this survey. Improvements in QOL and symptoms following treatment with such agents may be clarified as uptake increases in the coming years. A total of 61 participants reported treatment with saline laxatives and agents, which depress acid secretion. Owing to the mechanisms of action of these drugs, it seems likely that inhibition of gastric acid secretion may diminish the laxative effect. ${ }^{21}$ Thus, physicians must take care when co-prescribing GERD and constipation treatments to ensure that both conditions are adequately treated. A recent study reported that $38.3 \%$ of patients with GERD and $21.3 \%$ of patients without GERD were prescribed laxatives in a university hospital outpatient setting. ${ }^{22}$ Interestingly, despite not stipulating current clinic attendance, the present study data were similar, indicating a rate of constipation medication prescribing of $32.9 \%$ in GERD groups and 24.4\% in non-GERD groups (Supplementary Table 7).

Limitations of the REACTION-J2 study include the survey format and the reliance on self-reported information without confirmation from medical records. Additionally, participants required internet access to participate in the study. As such, Japanese patients older than 70 years of age may not be appropriately represented in the study population. Finally, our survey was conducted in a Japanese population, and further validation of the results in nonJapanese individuals is warranted.

In conclusion, we confirmed the prevalence of constipation and GERD in Japan. In participants with both disorders, QOL was worsened compared with participants who only had GERD or constipation. Participants with both disorders appear to be receiving insufficient treatment. Prompt prescription of medical treatment is 
useful to improve symptoms in patients who have either GERD, constipation, or both. Finally, we have shown the relevance of conducting a detailed evaluation of overlapping constipation and GERD in Japan.

\section{Supplementary Materials}

Note: To access the supplementary method and tables mentioned in this article, visit the online version of Journal of Neurogastroenterology and Motility at http://www.jnmjournal.org/, and at https://doi.org/10.5056/jnm21065.

Acknowledgements: We thank Sally-Anne Mitchell, $\mathrm{PhD}$, of Edanz (www.edanz.com), for providing medical writing support, which was funded by EA Pharma Co, Ltd, Tokyo, Japan. The data have been previously reported in an oral presentation (S6-2, Symposium 6) at the 107th General Meeting of the Japanese Society of Gastroenterology, on 17 April 2021.

Financial support: This study was funded by EA Pharma Co, Ltd.

Conflicts of interest: Naotaka Ogasawara and Yasushi Funaki report receiving expenses related to this study from EA Pharma Co, Ltd. Kunio Kasugai reports receiving expenses related to this study from EA Pharma Co, Ltd; research funding from EA Pharma Co, Ltd; and scholarship donations from AstraZeneca and Daiichi Sankyo Co, Ltd. Masahide Ebi, Yasuhiro Tamura, Shinya Izawa, and Makoto Sasaki report receiving expenses related to this study from EA Pharma Co, Ltd.

Author contributions: Conceptualization: Naotaka Ogasawara, Kunio Kasugai, and Masahide Ebi; methodology, formal analysis, and investigation: Naotaka Ogasawara, Yasushi Funaki, Yasuhiro Tamura, and Shinya Izawa; writing - original draft preparation: Naotaka Ogasawara; writing - review and editing: Naotaka Ogasawara, Yasushi Funaki, Kunio Kasugai, and Makoto Sasaki; and funding acquisition, resources, and supervision: Kunio Kasugai.

\section{References}

1. De Giorgio R, Ruggeri E, Stanghellini V, Eusebi LH, Bazzoli F, Chiarioni G. Chronic constipation in the elderly: a primer for the gastroenterologist. BMC Gastroenterol 2015;15:130.

2. Gallegos-Orozco JF, Foxx-Orenstein AE, Sterler SM, Stoa JM. Chronic constipation in the elderly. Am J Gastroenterol 2012;107:18-25.

3. Ministry of Health, Labour and Welfare. National survey of basic life
2016. Available from URL: https:/www.mhlw.go.jp/toukei/saikin/hw/ktyosa/k-tyosa16/dl/06.pdf (accessed 9 Nov 2021).

4. Tamura A, Tomita T, Oshima T, et al. Prevalence and self-recognition of chronic constipation: results of an internet survey. J Neurogastroenterol Motil 2016;22:677-685.

5. Kasugai K, Yamamoto S, Kawamura Y, et al. [Internet survey of the actual situation of constipation in Japanese general population REACTION$\mathrm{J}$ : research for actual situation of constipation in the Japanese.] Nihon Shokakibyo Gakkai Zasshi 2019;116:913-926. [Japanese]

6. Suzuki H. [Approach to chronic constipation overlap with functional gastrointestinal diseases.] Medicina 2016;53:2016-2018. [Japanese]

7. Nakashima S. [Functional gastrointestinal disorders (FGID): progress in diagnosis and treatments. Topic I. Basic knowledge of functional gastrointestinal disorders (FGID); 6. Definition and overlaps of functional gastrointestinal disorders.] Nihon Naika Gakkai Zasshi 2013;102:40-45. [Japanese]

8. Taub E, Cuevas JL, Cook EW 3rd, Crowell M, Whitehead WE. Irritable bowel syndrome defined by factor analysis. Gender and race comparisons. Dig Dis Sci 1995;40:2647-2655.

9. Siah KTH, Gong X, Yang XJ, et al. Rome Foundation-Asian working team report: Asian functional gastrointestinal disorder symptom clusters. Gut 2018;67:1071-1077.

10. Iwakiri K, Kinoshita Y, Habu Y, et al. Evidence-based clinical practice guidelines for gastroesophageal reflux disease 2015. J Gastroenterol 2016;51:751-767.

11. Locke GR 3rd, Zinsmeister AR, Fett SL, Melton LJ 3rd, Talley NJ. Overlap of gastrointestinal symptom complexes in a US community. Neurogastroenterol Motil 2005;17:29-34.

12. Baran M, Özgenç F, Arikan Ç, et al. Gastroesophageal reflux in children with functional constipation. Turk J Gastroenterol 2012;23:634-638.

13. Dehghani SM, Poorghaiomi R, Javaherizadeh H. Clinical manifestation of gastroesophageal reflux among children with chronic constipation. Middle East J Dig Dis 2020;12:178-181.

14. Lacy BE, Mearin F, Chang L, et al. Bowel disorders. Gastroenterol 2016;150:1393-1407.

15. Jones R, Junghard O, Dent J, et al. Development of the GerdQ, a tool for the diagnosis and management of gastro-oesophageal reflux disease in primary care. Aliment Pharmacol Ther 2009;30:1030-1038.

16. Svedlund J, Sjödin I, Dotevall G. GSRS--a clinical rating scale for gastrointestinal symptoms in patients with irritable bowel syndrome and peptic ulcer disease. Dig Dis Sci 1988;33:129-134.

17. Tokuda Y, Okubo T, Ohde S, et al. Assessing items on the SF-8 Japaneseversion for health-related quality of life: a psychometric analysis basedon the nominal categories model of item response theory. Value Health 2009;12:568-573.

18. Agachan F, Chen T, Pfeifer J, Reissman P, Wexner SD. A constipation scoring system to simplify evaluation and management of constipated patients. Dis Colon Rectum 1996;39:681-685.

19. Kusano M, Shimoyama Y, Sugimoto S, et al. Development and evaluation of FSSG: frequency scale for the symptoms of GERD. J Gastroenterol 2004;39:888-891.

20. Suzuki H, Matsuzaki J, Okada S, Hirata K, Fukuhara S, Hibi T. 
Validation of the GerdQ questionnaire for the management of gastrooesophageal reflux disease in Japan. United European Gastroenterol J 2013;1:175-183.

21. Yamasaki M, Funakoshi S, Matsuda S, et al. Interaction of magnesium oxide with gastric acid secretion inhibitors in clinical pharmacotherapy.
Eur J Clin Pharmacol 2014;70:921-924.

22. Momma E, Koeda M, Tanabe T, et al. Relationship between gastroesophageal reflux disease (GERD) and constipation: laxative use is common in GERD patients. Esophagus 2020;18:152-155. 